\title{
Assessment for Student Success: Delivering High-Quality Modules and Improving Educational Methods in Civil Engineering Program
}

\author{
Eyad Abushandi \\ Civil Engineering Stream, \\ Faculty of Engineering, \\ Sohar University, Al Jamiah Street, \\ Sohar OM, 311, Oman; \\ Centre for Learning and Teaching, \\ Edge Hill University, \\ St Helens Rd, Ormskirk L39 4QP, \\ United Kingdom
}

DOI: https://doi.org/10.36941/jesr-2021-0044

\begin{abstract}
There are many internal and external factors influence student success such as optimization of student support services, campus resources, teaching methods and learning outcomes achievement, and many others. Understanding student success due to the global declining quality of undergraduate engineering students is very demanding. Post training or re-educating graduates is expensive and time consuming and can be prevented by if structured educational process took a place. The aims of this study were to identify student's success related factors and assess how a new teaching method will impact student success. Assessment of student success within civil engineering major was analyzed. After conducting the teaching method, a structured reflective questionnaire was carried out among 50 students targeting two modules namely traffic and transportation engineering from level three, and introduction to structural analysis and design from level two. Students' satisfaction and teaching method effectiveness emerged as significant indictors of student success. Statistical analysis was performed to evaluate student responses. Person correlation and Multiple Linear Regression were used to test and predict the relationships between the variables mainly gender, teaching method effectiveness, and overall evaluation. Gender plays a moderate to strong role in the response for method effectiveness indicator and overall evaluation indicators. The performance of Multiple Linear Regression was exceptionally well with very low average relative error (5\%). Students are more likely to be engaged onsite rather than online to adjust their need and trigger academic support. Improving student support services, student's engagement, and update module materials to be more problem based are recommended to ensure students success. In addition, proper student's feedback analysis, formative and summative assessments were primary tools to improve teaching practices.
\end{abstract}

Keywords: students' success, teaching methods, success factors, statistical analysis

\section{Introduction}

Generally, the mission of Sohar University is to help students engage their minds and transform important knowledge in order to serve the community. Elemental to this mission is ensuring that 
teachers understand instructional planning of student success. (Ewell and Wellman, 2007) defined student success as "getting students into and through college to a degree or certificate". In other words, students achieved the desired learning outcomes are under a success criterion. While student success must be sensitive to economic condition and workforce development needs (Kuh et al., 2007), many educational institutes consider student success is part of one or more from the following criteria:

1. High retention and graduation rates,

2. High student's satisfaction rates,

3. Accelerated progression,

4. Acquisition of graduate attributes,

5. High employability rate,

However, many definitions are focusing on the academic approach only while missing some core elements and phases in the broader environment such as soft skills, diverse needs of growing market, and students-campus integration. Therefore, it's important to create an emerging student success framework to include all related aspects.

At a micro-scale level, many teachers are evaluating the students learning outcomes by giving tests or assignments. Although they are important; these activities might help students to achieve the major attribute of the module such as problem-solving ability, and/or academic skills. Students who pass those tracks might be able or unable to apply the gained knowledge to a real situation occurred during their jobs. The target of understanding the track is to successfully transform students from academic community to society with high ability to solve the challenges of a rapid development environment.

Student success approach has been investigated by many literature including additional aspects and representing new dimensions and indicators. The first effort on student success was published by John McNeely in 1938 when he defined student mortality as the "failure of students to remain in college until graduation"(McNeely, 1938). Later the definition has been termed to be much more upon empirical investigation. (York and MacAlister, 2015) defined academic student success as an academic achievement, satisfaction, attainment of learning objectives, acquisition of oriented skills, and post college performance. An intensive analysis on student success by (Kuh et al., 2007) concluded success is a multiple desired outcomes. Other researchers indicated that high grades are not always precise in measurement learning ability (Kuncel and Hezlett, 2007; Denham et al., 2018; Gunawan, 2018; van der Zanden et al., 2018; Lilleholt et al., 2019). High grades, however, might mislead the teachers on student success concept. Later, graduates with high GPAs cannot find a job as they lack the required skills and knowledge. According to (Gewertz, 2011) students enter university with deficiencies in reading, writing, and mathematics will probably not success. High school and foundation program preparation is one important factor in helping student to perform well and to be engaged in the degree. (Berry, 2003) investigated the gap between high school and the college to improve student. She found out that students who have taken sufficient college preparatory coursework in high school can pass easily the related course in the college.

\section{Student Success Factors}

Student success is part of a bigger image of success starting from the module which is directly connected to other larger scale such as program, university; and national environments (Figure 1). The requirements of each environment can force the module to change in one direction or another.

In fact, there are different key factors influencing students' success, particularly, at Sohar University. I categorized the factors into internal and external based on my personal perception. 


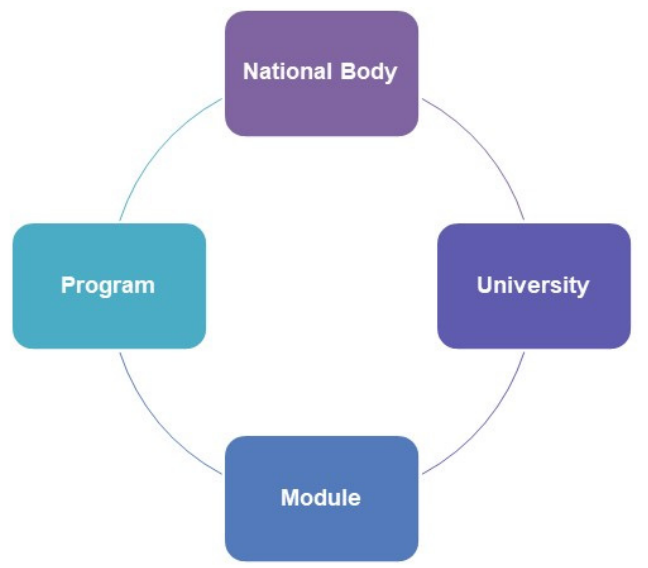

Figure 1: Success related environments

\subsection{Internal Factors}

1) University environment and infrastructure: Sohar University includes modern classrooms, halls, learning resources centre, centre for educational development, libraries, and many other facilities to create all possible environments for student's development and growth. Strange and Banning (2015) framed one conceptual theme related to create campus environments for student success, mentioning that students will attempt to cope any educational environment. If the environment is not compatible with the students, the students may react negatively or fail to develop the desired quality (Strange and Banning, 2015).

2) University regulations and policies: Students success at Sohar University is heavily influenced by the university regulation and codes. Civil engineering stream does not create its own policies but implements university policies. According to (Tinto and Pusser, 2006) policies at all levels (Figure 2) should place a high priority on achieving student success. The policies are usually interconnected and include goals on how students will be better served.

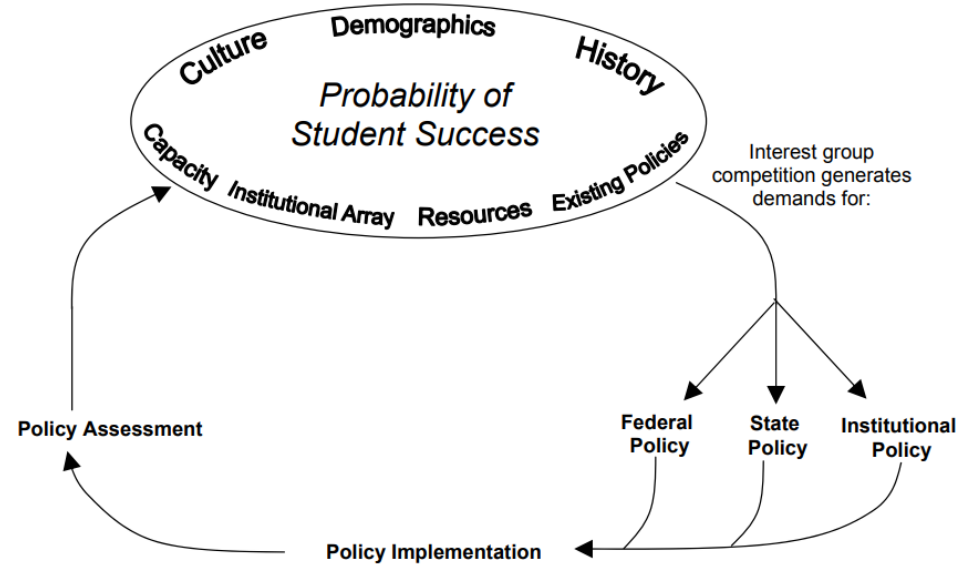

Figure 2: Policy and student success (Tinto and Pusser, 2006) 
3) Module Learning Outcomes (CLOs) design and assessment: based on study level each module has a couple of LOs reflecting what the students should master by the end of the module. Usually, practicing different teaching methods is required to achieve the LOs including problem-based learning, cooperative learning, and many others. However, student's feedback of the assessments plays a major rule in defining module strengths, weaknesses, opportunities, and threatens. Consequently, answering the question whether teaching activities for next semester or even next lecture will take the same track or not.

4) Management of the module \& program quality assurance: it's a requirement to review the taught modules at the end of each semester and update module's profile and portfolio to answer two major questions what went well or what was the problem. In general, the problem can be minor or major based on its impact on student performance and success. The new improvement has to take place for the successive semester. Thus, the practice will be changed to meet the new implementations.

5) Qualifications and experience: in addition to the years of experience; teacher study and teaching backgrounds are playing a rule of daily teaching practices and adding a great value to student success.

6) Student support services (SSS): this factor covers many areas such as academic advising, admission unit, financial aid, placement and counseling, and delivery of extracurricular activities such as workshops and trainings. In my personnel view, SSS gives me an opportunity to interact with students and access several types of problems they face. In fact, this can impact my teaching behavior. According to (Cummings, 2014) students engaged in Student Support Services desired to be in the program and took personal ownership of their academic success.

7) Student Engagement: Student engagement represents the intersection of student behaviors and education provider conditions. according to (Fredericks et al., 2004) there are three types of students engagement:

i. behavioral engagement: students' participation in education, including the academic, social and extracurricular activities.

ii. emotional engagement: students' reactions in the classroom and in the campus

iii. cognitive engagement: students' investment in their learning (motivation and selfregulation).

In addition, (Villiers and Werner, 2018) summarized the factors contributing towards students engagement mainly academic focus, student-staff interaction, social integration, and campus support and infrastructure.

8) Student Motivation: Student's motivation has been considered as a significant factor in student success. Recently it has become a major focus of research on academic learning (Anderman and Dawson, 2011). In education, the researchers attempt to explain how students strive for particular goals, how long they strive, and what feelings and emotions characterize them in the process (Glynn et al., 2005). Academically, motivated students achieve the learning outcomes through engagement in behaviour such as self-learning, question asking, advice seeking, and participating in classes, labs, and study groups (Schunk et al., 2008).

9) Teaching load and research activities: a heavy teaching load can reduce teaching efficiency and makes research activities much more difficult. In fact, to balance the time between research and teaching a reasonable teaching load and student number in the classroom will impact student success.

10) Student nationality and gender: apart from Omani students' majority classrooms there are minority of international students mainly from India, Pakistan, Egypt, and others countries. This reflects the diversities of student's background, English language skills, and performance levels. In some case, I noticed some weaknesses in the prerequisites math and physics courses which force me to give additional example to unify students' levels in a particular subject. Around $80 \%$ of engineering students are girls who have different interest than boys which 
add more challenges to balance the lecture. Apart from socioeconomic and demographic factors girls usually are better performing than boys.

\subsection{External Factors}

1) Ministry of Higher Education: the ministry regulations and decisions affect the university regulation and policies. Consequently, affect university policies in order to meet such requirements. Entry requirements and the number of students funded by the ministry are changing dramatically from year to another. This will impact the services provided by the university.

2) National Competition: Apart from Sohar University the city has three academic colleges namely:

i. College of Applied Sciences Sohar

ii. International Maritime College Oman

iii. Oman Medical College

This creates a competitive environment for Sohar University to survive and provide better academic quality

3) Relationships with the Community: there are continuous efforts to engage local community and stakeholders in our educational process through open discussions. Their proposals have been taken seriously to improve our practice.

\section{Project Objective and Scope}

The objectives of this research project are to provide more insight into how student's success is connected to many associated variables and assess how a new teaching method will impact student success. In order to achieve these objectives, the research will explore the attributes of quality teaching practices and find the critical intersections between defined factors to understand student success concept within three major areas:

1. The development of students' academic skills,

2. The impact of students' assessment and feedback,

3. The behavior of students to different teaching methods, materials and assignments.

\section{Research Questions}

In this project I will try to answer the following questions:

1. What is the focus on student success in Oman?

2. What are the driving forces for student success?

3. What are the principles of designing student success?

4. What types of assessments help student success?

\section{Research Design and Methodology}

A mixed methods sequential approach developed by (Creswell and Creswell, 2014) has been implemented for this study (Figure 3). The reason of using this approach is because it provides a final phase of integration or linking the data from different sources. In addition, decide on the priority or weight given to collected data and at which level the variables are connected. A structured survey was conducted and aimed to collect data on a range of issues related to above mentioned factors where internal and external factor ranked from o to 4 . The research survey form included a 50 responses sample from civil engineering full time students from two different modules namely:

1. Traffic and Transportation Engineering (CIVE 3410), Level 3

2. Introduction to Structural Analysis and Design (CIVE2320), Level 2 
Due to current condition of COVID 19 the survey was distributed using Google form. The aim of this survey was to get student feedback on the teaching. Table 1 shows the questions as well as the possible answers.

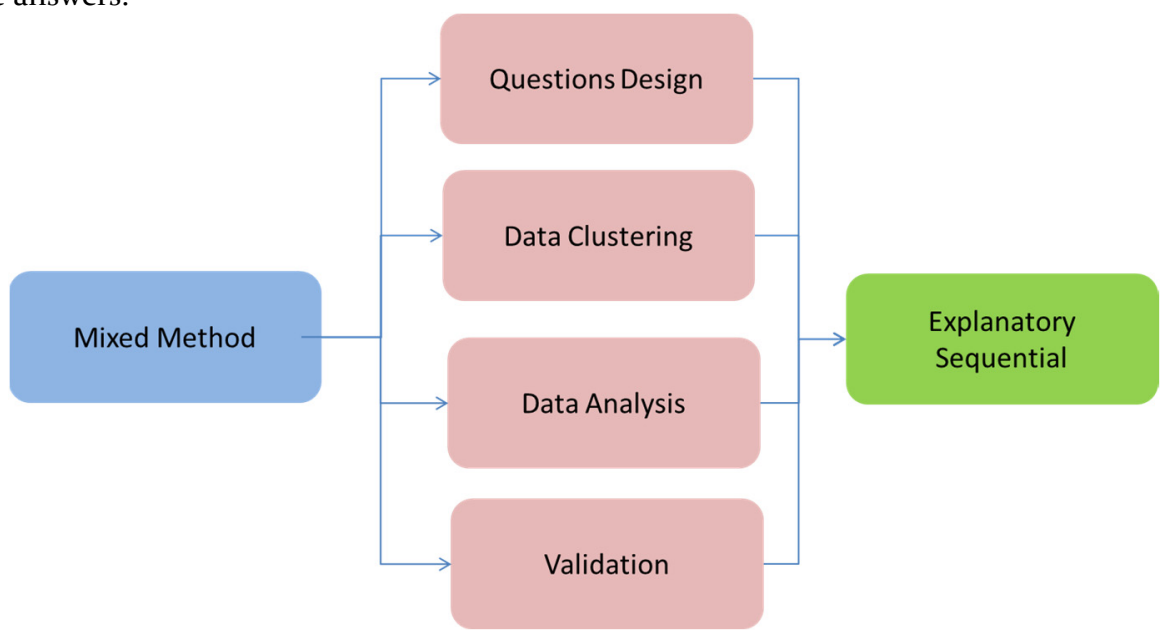

Figure 3: Research framework

Table 1: Survey major questions and possible answers

\begin{tabular}{|c|c|}
\hline Question & Possible answers \\
\hline 1. Gender & $\begin{array}{l}\text { o Male } \\
\text { o Female }\end{array}$ \\
\hline 2. Course Name & $\begin{array}{l}\text { Introduction to Structural Analysis and Design (CIVE2320) } \\
\text { ○ Traffic and Transportation Engineering (CIVE3410) }\end{array}$ \\
\hline $\begin{array}{l}\text { 3. How effective was the teaching methods } \\
\text { within your module? }\end{array}$ & $\begin{array}{l}\text { o Extremely useful } \\
\text { o Very useful } \\
\text { o Moderately satisfied } \\
\text { o Slightly satisfied } \\
\text { o Not at all satisfied }\end{array}$ \\
\hline $\begin{array}{l}\text { 4. Overall, were you satisfied with your } \\
\text { experience at this module? }\end{array}$ & $\begin{array}{l}\text { o Extremely satisfied } \\
\text { o Very satisfied } \\
\text { o Moderately satisfied } \\
\text { o Slightly satisfied } \\
\text { o Not at all satisfied }\end{array}$ \\
\hline 5. How do you define student success? ${ }^{*}$ & $\begin{array}{l}\text { o Entering college and remain, re-enroll, and continue from one } \\
\text { level to another } \\
\text { o High marks of the course } \\
\text { o Completion of the degree } \\
\text { o Enter gainful career (job) after completing the degree } \\
\text { o Attending master's degree after completing the current degree }\end{array}$ \\
\hline $\begin{array}{l}\text { 6. What was your favorite experience in this } \\
\text { module?* }\end{array}$ & $\begin{array}{l}\text { o Questions may have different solutions } \\
\text { o Questions require short answers } \\
\text { o Questions may need to read from internet } \\
\text { o Questions include local problems in Sohar }\end{array}$ \\
\hline $\begin{array}{l}\text { 7. The most effective classes were delivered } \\
\text { online or onsite. }\end{array}$ & $\begin{array}{l}\text { o Online } \\
\text { o Onsite } \\
\text { o Both are effective }\end{array}$ \\
\hline
\end{tabular}

\footnotetext{
* one or more answers can be selected
} 


\subsection{Data Processing}

Data processing basically needs a good processing strategy to ensure higher accuracy. Students' responses were converted into numeric values in order to understand the relationships between the variables and interpret the concepts using Statistical Package for the Social Sciences (SPSS). Students may have one or more answers for some questions; therefore, several digits were used to differentiate between the responses. Further steps were also included such as:

i. Frequency

ii. Pearson correlation

iii. and Linear Regression (MLR).

Linearity was measured using the Pearson correlation.

$$
\mathbf{r}=\frac{\mathbf{N} \sum \mathbf{x y}-\left(\sum \mathbf{x}\right)\left(\sum \mathbf{y}\right)}{\sqrt{\left[\mathbf{N} \sum \mathbf{x}^{2}-\left(\sum \mathbf{x}\right)^{2}\right]\left[N \sum \mathbf{y}^{2}-\left(\sum \mathbf{y}\right)^{2}\right]}}
$$

Where $\mathrm{x}$ is the independent variable (factors), $\mathrm{y}$ is the student response and $\mathrm{N}$ is the number of the records.

\subsection{Multiple Linear Regression Description}

Multiple Linear Regression (MLR) estimates the relations between two or more variables. Since the factors have a direct effect on student's responses, the variables are hypothesized to be in a cause-andeffect relationship (e.g. gender, students' satisfaction, and teaching method effectiveness). The data for linear regression analysis were collected from the Google form questionnaire. The linear regression model assumes that there is a linear, or "straight line" -but the line is not necessarily horizontalrelationship between the dependent variable and the independent variable. This relationship is described in the following formula:

$$
y_{i}=b_{0}+b_{1} x_{i 1}+\ldots+b_{p} x_{i p}+e_{i}
$$

Where

$y_{i}$ : is the value of the $i^{\text {th }}$ case of the dependent scale variable

$p$ : is the number of predictors

$b_{j}$ :is the value of the $j^{\text {th }}$ coefficient, $j=0, \ldots, p$

$x_{\mathrm{ij}}$ : is the value of the $i^{\text {th }}$ case of the $j^{\text {th }}$ predictor

$e_{i}$ : is the error in the observed value for the $i^{\text {th }}$ case

\section{$5 \cdot 3$ Task design}

The task of problem-based learning was successfully implemented depending on three major parameters:

1. Design: Proper design of the given task is needed to avoid confusion or lack of specification. In advance levels of engineering, the best design for the task is to link the theory in the lecture with real local or national dilemma. For instance, in Traffic and Transportation Engineering module, I introduced signal optimum cycle time design in an intersection close Sohar city suffers an often traffic problem. Commonly, I introduced the tasks in the lecture time to provide a context and point out the activities, strategies to solve the problem, and explain the list of given supplementary documents (excel sheet on traffic flow). However, real problem solving is not applicable for all engineering levels and disciplines such as mathematical foundation in level one.

2. Resources: Adequate resources to solve the problem must be available but not all data should be provided in order to encourage students to explore a variety of resources. Nowadays, virtual teaching is demanding in order improve students' abilities. The problem has been 
solved by requesting to extract required field data from Google earth.

3. Assessment: Assessment is an essential part of education process to examine whether the course learning outcomes are being achieved or not. It's very difficult to assess problemsbased learning without proper evaluation rubrics which must reflect students' differences and ensure the achievement of course learning outcome. Therefore, the possible solution scenarios to solve given problem were prepared. My assessment includes a combination of individual reports, and discussions. It's important to explain the assessment strategy to the students in advance because a full understanding of how they will be assessed is part of their road to success.

\section{Results and Discussion}

Respondents were requested to complete demographic information (e.g. gender) and other features to test whether gender plays a role in their responses or not. The numbers of male and female contributed in this study were roughly equal 54 percent to 46 percent consequently (Figure 4). Similarly, the responses from level two student's module; Introduction to Structural Analysis and Design (CIVE2320); were 46 percent, while from level three student's module Traffic and Transportation Engineering (CIVE3410) were 54 percent (Figure 5). These contributions indicated that students from the two levels were engaged in the survey and took the request seriously.

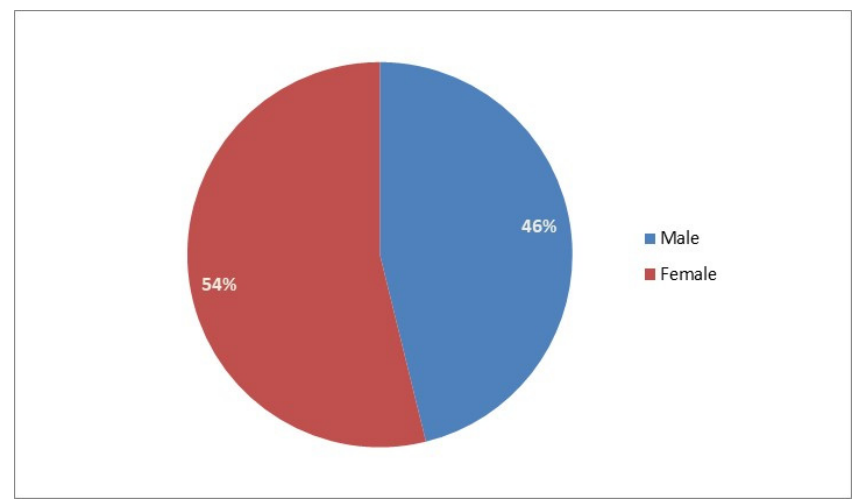

Figure 4: Gender distribution in the survey

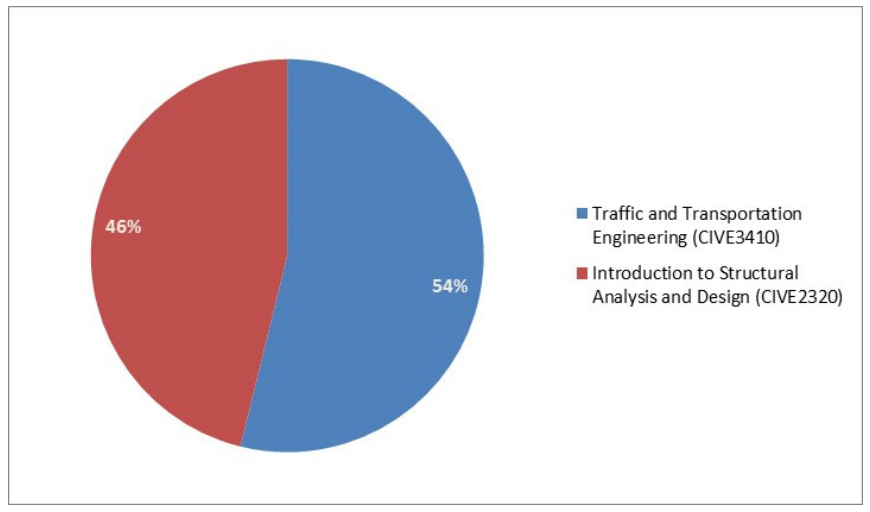

Figure 5: Modules distribution in the survey 
Table 2 shows more details on statistical elements such as mean, standard deviation, variance, and std. error of mean.

Table 2: Descriptive statistics

\begin{tabular}{|l|l|c|c|c|c|c|}
\hline & & Gender & Modules Name & Teaching Effectiveness & Q2 & Success Definition \\
\hline \multirow{2}{*}{$\mathrm{N}$} & 50 & 50 & 50 & 50 & 50 \\
\cline { 2 - 7 } & Malid & $\mathrm{o}$ & $\mathrm{O}$ & $\mathrm{0}$ & $\mathrm{O}$ & $\mathrm{0}$ \\
\hline Mean & .46 & $\mathbf{2 . 5 4}$ & $\mathbf{2 . 8 8}$ & $\mathbf{2 . 8 0}$ & 3.86 \\
\hline Std. Error of Mean & .071 & .071 & .150 & .131 & .270 \\
\hline Std. Deviation & .503 & .503 & 1.062 & .926 & 1.906 \\
\hline Variance & .253 & .253 & 1.128 & .857 & 3.633 \\
\hline
\end{tabular}

Effective teaching method requires an implementation of creative strategy in order to meet the individual needs. Unfortunately, due to the current situation of COVID-19 pandemic, the plan was changed adding one more challenge for not being able to teach onsite. To overcome this situation, digital solutions were made to explain and refine the task including:

i. $\quad$ video records uploaded on YouTube

ii. power point presentations with audio records uploaded on Sohar University Learning Management Systems (SULMS)

It's worth to mention that the module materials have been totally modified by adding more flowcharts, colors, and pictures. In addition, students were able to contact or share their thought using MS Teams, Zoom, or WhatsApp to ensure that all students receive the same amount of information; announcements and video conferences were regularly made.

Effective teaching method requires an implementation of creative strategy in order to meet the individual needs. Generally, students showed an agreement on the method of teaching used during this semester was effective in a range between very useful to extremely useful with percentages of $48 \%$ and $27 \%$ respectively (Figure 6 ). In terms of gender, females seemed to be much more comfortable on the method of teaching than males where Pearson correlation was o.643. More details on Pearson correlation values are provided in the appendix.

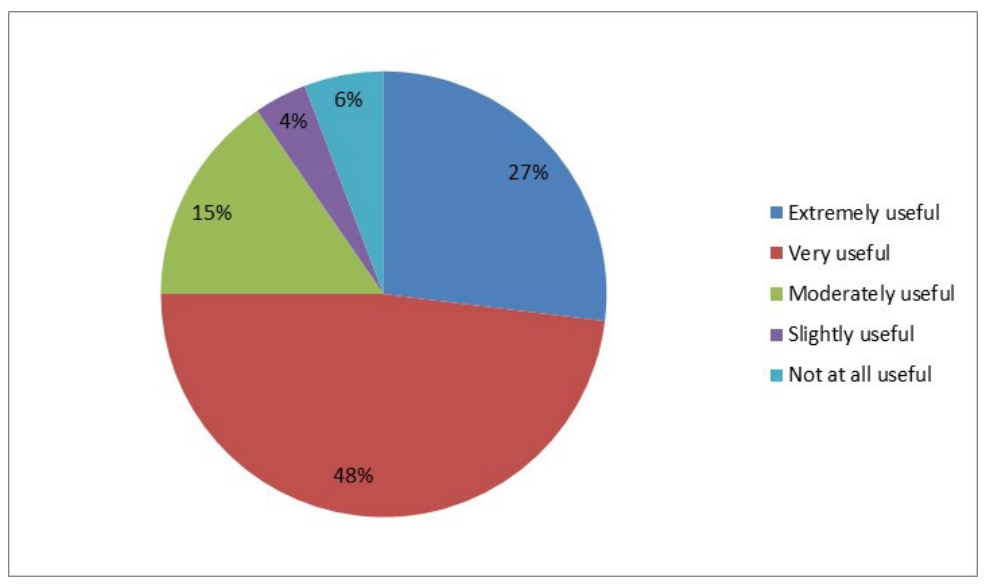

Figure 6: Teaching method effectiveness

Moreover, level of student satisfaction is the most difficult and demanding parameter to measure. Generally, students reflected a good level of satisfaction with the task given during this semester 
(Figure 7). The results showed that around $71 \%$ of the sample perceived a range of very to extremely satisfied. Based on some students' online interviews, there is an opportunity to improve satisfaction level by improving student support services, students' engagement, and university facilities particularly online resources.

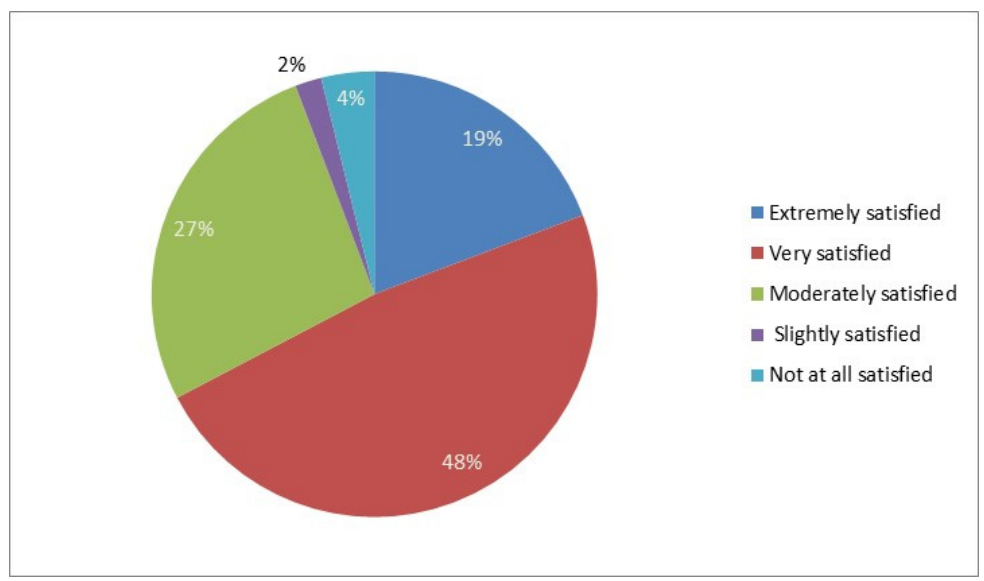

Figure 7: Overall evaluation

As previously mentioned, research suggested student's engagement, graduation, career attainments may provide a clear picture of students' success. Therefore, one of the survey questions was to know how students think about success. Although students could choose more than one answer, diverse of responses have been received which reflect the reality of not having a clear definition of success (Figure 8). While 14 students selected more than one choice, traditional student understanding of success includes high marks (33\%) along with entering college and remain, re-enroll, and continue from one level to another (33\%). Unfortunately, the lowest responses were for entering gainful career (job) after completing the degree with rate of $19 \%$. According to Pearson correlation values, there is a significant correlation between responses of teaching method effectiveness and success definitions with a value of o.79. In addition, the students showed a consistency of the level of satisfaction and students success definition, while gender or study level didn't influence those factors.

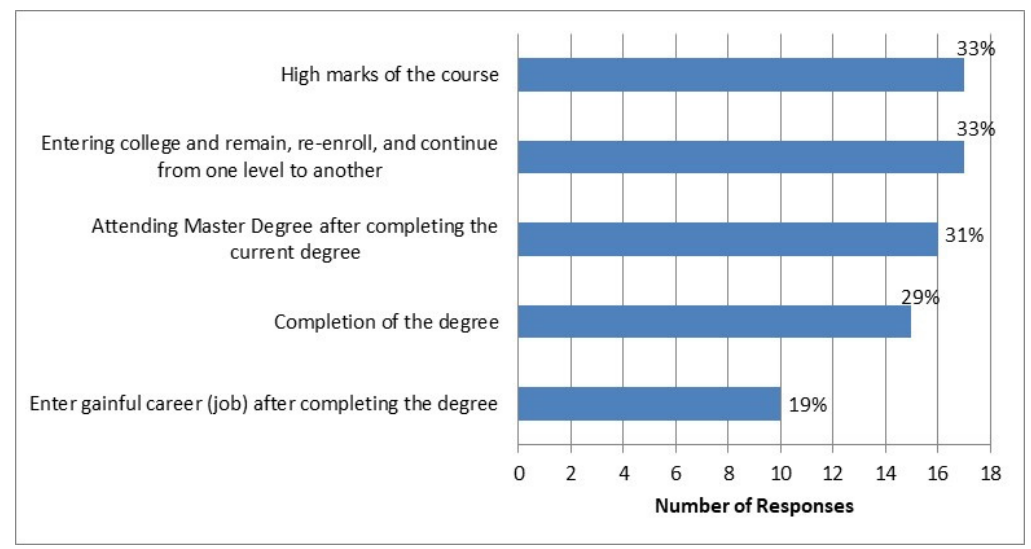

Figure 8: Student success definitions 
The task in this study was based on Problem Based Learning giving students the responsibility for their own learning activities. Regardless the module topics, Problem Based Learning method has been widely implemented in many education disciplines such as medicine (Martínez-Jarreta et al., 20o9; Rovers et al., 2018; Wang et al., 2018; Zhao and Cong, 2019) engineering (Vega and Navarrete, 2019; Joshi et al., 2020) and information technology (Ismail et al., 2018) to improve critical thinking skills and selflearning responsibility. The questionnaire included a question on teaching method types (Figure 9). In comparison with other activities given to the students, problem-based learning task has taken the highest rank of student's favorite experience. In this manner, there are four components may have led the students to response in such way namely:

i. the task has a clear objective,

ii. the task starts with real problem to enhance critical thinking,

iii. the task encourages students self-learning,

iv. the task is an outcome based.

In addition, there was an ongoing formative feedback which helped both students and me to recognize where the student's strengths and weaknesses are. Brain storming questions, hints, and discussions are examples to overcome some issue in the task. In terms of summative assessment, the questions include real data and open-ended answers which means students will have different solutions based on their understanding. Most importantly the assessment period should be suitable to solve the given questions. It has been considered that students' requirements are different at each level of study, even at the same level for a different year. Therefore, it's important for me to properly change the structure to improve students understanding and create a desirable learning environment.

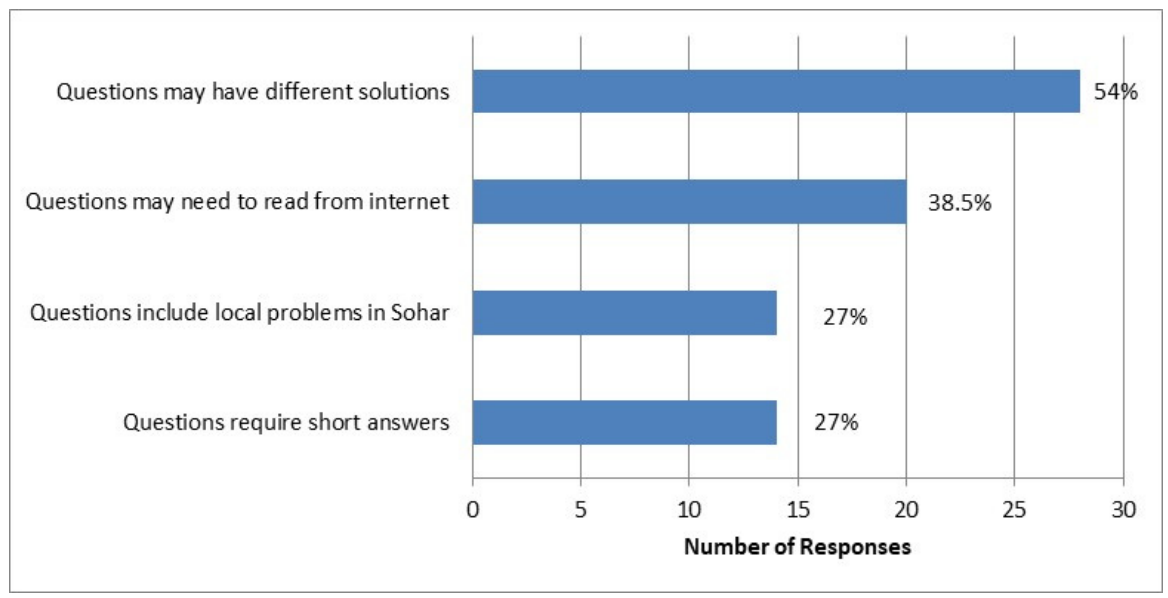

Figure 9: Favorite experience in this module

The most effective classes were delivered onsite. Most students were highly motivated to attend onsite classes rather than online. Even students were engaged in regular discussions, online class has taken a lower responses rate (Figure 10). Perhaps they missed the social and emotional supports and greater engagement in learning activities. 


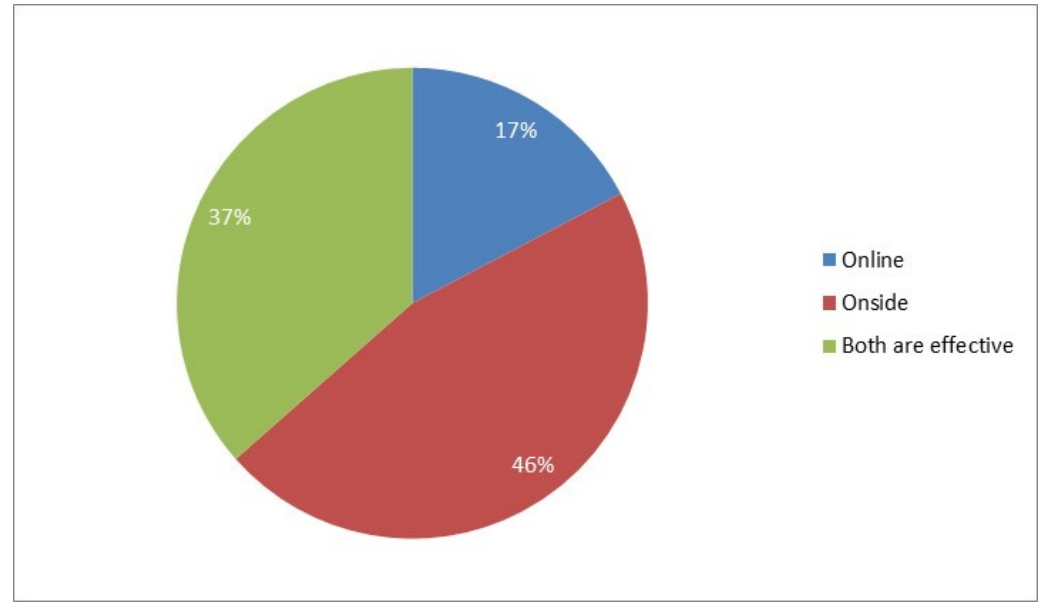

Figure 10: The most effective classes were delivered online or onsite

As per the results, the functional relationship was found to be significant between the gender, teaching method and overall evaluation. The linearity of student's responses was observed by many researchers e.g. (Porter et al., 2004; Modestou and Gagatsis, 2007; Young-Jones et al., 2013). However, researchers attempted to investigate several study programs, boarder cases (e.g. foundation year or last year), and bigger sample of population. For regression analysis the input data were two variables (gender and teaching effectiveness), while the dependent variable was student overall evaluation. The resulting linear equation to estimate shoreline volume losses as following:

Overall evaluation $=0.828-($ Gender $\times 0.132)+($ Teaching effictivness $\times 0.706)$

The coefficients of regression variables entered to the SPSS are shown in Table 3.

Table 3: MLR model Coefficients

\begin{tabular}{|c|c|c|c|c|c|}
\hline \multirow{2}{*}{ Model } & \multicolumn{2}{|c|}{ Unstandardized Coefficients } & Standardized Coefficients & \multirow{2}{*}{$\mathrm{t}$} & \multirow{2}{*}{ Sig. } \\
\hline & $\mathrm{B}$ & Std. Error & Beta & & \\
\hline (Constant) & .827 & .237 & & 3.495 & .001 \\
\hline 1 Gender & -.132 & .158 & -.072 & -.836 & .407 \\
\hline Teaching Effectiveness & .706 & .075 & .810 & 9.414 & .000 \\
\hline
\end{tabular}

a. Dependent Variable: Overall Evaluation

Multiple linear regression (MLR) models showed relative errors less than 5\%. Most of the modelled values were underestimated ( 33 records) but very close to observed records. In addition, the average of modelled records was 2.78 while observed records average records was 2.80 of overall evaluation which indicate that MLR is performing exceptionally well (Figure 11). 


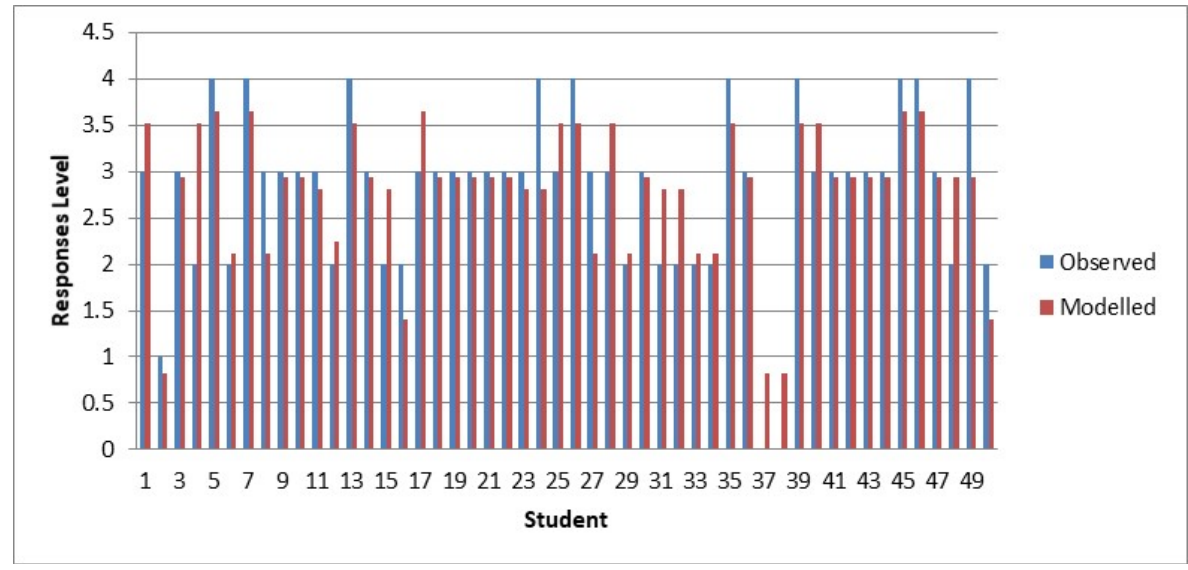

Figure 11: Observed and modelled responses of 50 students sample based on the linear regression model ranges from not useful to extremely useful.

Indeed, acquisition of data from different study level, module topic, or specialty may give different responses; thus, have slightly different levels of accuracy. Therefore, it is important to consider them, in addition to gender and teaching effectiveness responses.

\section{Conclusions}

In conclusion, there is a confusion of student success definition not only among students but also senior researchers. Students often look for new teaching methods and suitable environment to acquire knowledge and achieve their concept of success. Therefore, a proper design should be made to meet students learning needs. There are many interconnected factors can push student's success to risk. Although students' sample may appear to be diverse in terms of study levels and gender; the survey responses were fairly homogenous. There is a statistically significant correlation between gender, the acceptance of new teaching method, and overall evaluation. Limitation of the present project include is using online instead of onsite due to the global pandemic crises. The plan was to conduct the teaching method onsite, however, modifications have been made to meet current situation. Students' satisfaction and engagement can be better in case of onsite learning. In addition, it was not possible to investigate a single site impact on student success as we are not allowed to visit the library or other facilities. Future efforts should try to minimize those limitations, studying more indicators such as financial conditions, impact of campus facilities and centers, under preparation for college-level learning, and family condition, and working students. In addition, it's recommended to conduct the study on a bigger population sample.

\section{References}

Anderman, E., Dawson, H., 2011. Learning with motivation. In: P., A., R., M. (Eds.), Handbook of Research on Learning and Instruction. Taylor \& Francis

Berry, L., 2003. Bridging the gap: a community college and area high schools collaborate to improve student success in college. Community College Journal of Research and Practice 27, 393-407.

Creswell, J.W., Creswell, D., 2014. Research design: Qualitative, Quantitative, and Mixed Methods Approaches. SAGE 276.

Cummings, A., 2014. The Impact of Student Support Services on Academic Success at a Select Historically Black College and University. UNF. UNF, Florida, United State p. 196. 
Denham, S.A., Tietze, M., Allam, Z., Talleff, J., Schrum, N., Wang, T., 2018. Academic success of undergraduate nursing students. Nurse Education in Practice 33, 172-177.

Ewell, P., Wellman, J., 2007. Enhancing Student Success in Education. . Summary Report of the NPEC Initiative and National Symposium on Postsecondary Student Success. , U.S. Department of Education.

Fredericks, J.A., Blumenfeld, P.C., Paris, A.H., 2004. School engagement: potential of the concept, state of the evidence. . Review of Educational Research, 74, 59-109.

Gewertz, C., 2011. Higher ed.: Common core college-ready. . Education Week, , pp. 1-12.

Glynn, S., Aultman, L., Owens, M., 2005. Motivation to learn in general education progrms. The Journal of General Education 54, 150-170.

Gunawan, J., 2018. The value of the doctorate dissertation seminar to personal development. Nurse Education in Practice 33, A1-A2.

Ismail, N.S., Harun, J., Zakaria, M.A.Z.M., Salleh, S.M., 2018. The effect of Mobile problem-based learning application DicScience PBL on students' critical thinking. Thinking Skills and Creativity 28, 177-195.

Joshi, A., Desai, P., Tewari, P., 2020. Learning Analytics framework for measuring students' performance and teachers' involvement through problem based learning in engineering education. Procedia Computer Science 172, 954-959.

Kuh, G.D., Kinzie, J., Buckley, J., Bridges, B., Hayek, J.C., 2007. Piecing together the student success puzzle: Research, propositions, and recommendations. . In: Jossey-Bass (Ed.). ASHE Higher Education, San Francisco.

Kuncel, N.R., Hezlett, S.A., 2007. Standardized tests predict graduate students' success. Science 315, $1080-1081$.

Lilleholt, L., Aaby, A., Makransky, G., 2019. Students admitted to university based on a cognitive test and MMI are less stressed than students admitted based on GPA. Studies in Educational Evaluation 61, 170-175.

Martínez-Jarreta, B., Monsó, E., Gascón, S., Casalod, Y., Abecia, E., Kolb, S., Reichert, J., Radon, K., 20o9. e-Learning strategies in occupational legal medicine based on problems solving through "CASUS" system. Legal Medicine 11, $\mathrm{S}_{313-\mathrm{S}} 314$.

McNeely, J., 1938. College Student Mortality. U.S. Government Printing Office, University of Illinois at UrbanaChampaign.

Modestou, M., Gagatsis, A.J.E.P., 2007. Students' improper proportional reasoning: A result of the epistemological obstacle of "linearity". 27, 75-92.

Porter, S.R., Whitcomb, M.E., Weitzer, W.H.J.N.d.f.i.r., 2004. Multiple surveys of students and survey fatigue. 2004, 63-73.

Rovers, S.F.E., Clarebout, G., Savelberg, H.H.C.M., van Merriënboer, J.J.G., 2018. Improving student expectations of learning in a problem-based environment. Computers in Human Behavior 87, 416-423.

Schunk, D., Pintrich, P., Meece, J., 20o8. Motivation in education: theory, research, and applications (3rd ed.). Pearson/Merrill Prentice Hall.

Strange, C., Banning, J., 2015. Designing for Learning: Creating Campus Environments for Student Success. John Wiley \& Sons.

Tinto, V., Pusser, B., 2006. Moving From Theory to Action: Building a Model of Institutional Action for Student Success National Symposium on Postsecondary Student Success. National Postsecondary Education Cooperative.

van der Zanden, P.J.A.C., Denessen, E., Cillessen, A.H.N., Meijer, P.C., 2018. Domains and predictors of first-year student success: A systematic review. Educational Research Review 23, 57-77.

Vega, F., Navarrete, B., 2019. Professional design of chemical plants based on problem-based learning on a pilot plant. Education for Chemical Engineers 26, 30-34.

Villiers, B., Werner, A., 2018. The relationship between student engagement and academic success Journal for New Generation Sciences 14, 36-50.

Wang, M., Yuan, B., Kirschner, P.A., Kushniruk, A.W., Peng, J., 2018. Reflective learning with complex problems in a visualization-based learning environment with expert support. Computers in Human Behavior 87, 406-415.

York, T.W., MacAlister, D., 2015. Chapter 1 - The Healthcare Environment. In: York, T.W., MacAlister, D. (Eds.), Hospital and Healthcare Security (Sixth Edition). Butterworth-Heinemann, Boston, pp. 1-2o.

Young-Jones, A.D., Burt, T.D., Dixon, S., Hawthorne, M.J.J.Q.A.i.E., 2013. Academic advising: Does it really impact student success?

Zhao, X., Cong, L., 2019. Effect of problem and scripting-based learning combining wearable technology on orthopedic operating room nurses' learning outcomes. Nurse Education Today 73, 13-16. 


\section{Appendix}

Appendix-Table 1: Pearson correlation values of all interrelated factors

\begin{tabular}{|c|c|c|c|c|c|c|}
\hline & & Gender & Modules Name & Teaching Effectiveness & Overall & $\begin{array}{c}\text { Success } \\
\text { Definition } \\
\end{array}$ \\
\hline \multirow{3}{*}{ Gender } & Pearson Correlation & 1 & $.369^{* *}$ & .067 & -.018 & -.080 \\
\hline & Sig. (2-tailed) & & .008 & .643 & .904 & .579 \\
\hline & $\mathrm{N}$ & 50 & 50 & 50 & 50 & 50 \\
\hline \multirow{3}{*}{ Modules Name } & Pearson Correlation & $.369^{* *}$ & 1 & -.143 & -.158 & $.293^{*}$ \\
\hline & Sig. (2-tailed) & .008 & & .320 & .274 & .039 \\
\hline & $\mathrm{N}$ & 50 & 50 & 50 & 50 & 50 \\
\hline \multirow{3}{*}{ Teaching Effectiveness } & Pearson Correlation & .067 & -.143 & 1 & $.805^{* *}$ & -.039 \\
\hline & Sig. (2-tailed) & .643 & .320 & & .000 & .790 \\
\hline & $\mathrm{N}$ & 50 & 50 & 50 & 50 & 50 \\
\hline \multirow{3}{*}{ Overall } & Pearson Correlation & -.018 & -.158 & $.805^{* *}$ & 1 & -.039 \\
\hline & Sig. (2-tailed) & .904 & .274 & .000 & & .786 \\
\hline & $\mathrm{N}$ & 50 & 50 & 50 & 50 & 50 \\
\hline \multirow{3}{*}{ Success Definition } & Pearson Correlation & -.080 & $.293^{*}$ & -.039 & -.039 & 1 \\
\hline & Sig. (2-tailed) & .579 & .039 & .790 & .786 & \\
\hline & $\mathrm{N}$ & 50 & 50 & 50 & 50 & 50 \\
\hline
\end{tabular}

**. Correlation is significant at the o.o1 level (2-tailed).

*. Correlation is significant at the 0.05 level (2-tailed).

Appendix-Table 2: Gender frequency analysis

\begin{tabular}{|cc|c|c|c|c|}
\hline & & Frequency & Percent & Valid Percent & Cumulative Percent \\
\hline \multirow{4}{*}{ Valid } & 0 & 27 & 54.0 & 54.0 & 54.0 \\
& 1 & 23 & 46.0 & 46.0 & 100.0 \\
& Total & 50 & 100.0 & 100.0 & \\
\hline
\end{tabular}

Appendix-Table 3: Modules Name

\begin{tabular}{|cc|c|c|c|c|}
\hline & & Frequency & Percent & Valid Percent & Cumulative Percent \\
\hline \multirow{4}{*}{ Valid } & 2 & 23 & 46.0 & 46.0 & 46.0 \\
& 3 & 27 & 54.0 & 54.0 & 100.0 \\
& Total & 50 & 100.0 & 100.0 & \\
\hline
\end{tabular}

Appendix-Table 4: Teaching Effectiveness

\begin{tabular}{|cc|c|c|c|c|}
\hline & & Frequency & Percent & Valid Percent & Cumulative Percent \\
\hline \multirow{6}{*}{ Valid } & 0 & 3 & 6.0 & 6.0 & 6.0 \\
& 1 & 2 & 4.0 & 4.0 & 10.0 \\
& 2 & 7 & 14.0 & 14.0 & 24.0 \\
& 3 & 24 & 48.0 & 48.0 & 72.0 \\
& 4 & 14 & 28.0 & 28.0 & 100.0 \\
& Total & 50 & 100.0 & 100.0 & \\
\hline
\end{tabular}


Appendix-Table 5: Overall Evaluation

\begin{tabular}{|cc|c|c|c|c|}
\hline & & Frequency & Percent & Valid Percent & Cumulative Percent \\
\hline \multirow{4}{*}{ Valid } & 0 & 2 & 4.0 & 4.0 & 4.0 \\
& 1 & 1 & 2.0 & 2.0 & 6.0 \\
& 2 & 12 & 24.0 & 24.0 & 30.0 \\
& 3 & 25 & 50.0 & 50.0 & 80.0 \\
& 4 & 10 & 20.0 & 20.0 & 100.0 \\
& Total & 50 & 100.0 & 100.0 & \\
\hline
\end{tabular}

Appendix-Table 6: Success Definition

\begin{tabular}{|c|c|c|c|c|c|}
\hline & Frequency & Percent & Valid Percent & Cumulative Percent \\
\hline \multirow{6}{*}{ Valid } & 1 & 9 & 18.0 & 18.0 & 18.0 \\
& 2 & 7 & 14.0 & 14.0 & 32.0 \\
& 3 & 4 & 8.0 & 8.0 & 40.0 \\
& 4 & 6 & 12.0 & 12.0 & 52.0 \\
& 5 & 10 & 20.0 & 20.0 & 72.0 \\
& 6 & 14 & 28.0 & 28.0 & 100.0 \\
& Total & 50 & 100.0 & 100.0 & \\
\hline
\end{tabular}

